\title{
PRÁTICAS HUMANIZADAS DE GESTÃO DE PESSOAS E ORGANIZAÇÃO DO TRABALHO: PARA ALÉM DO POSITIVISMO E DO DATAÍSMO
}

\author{
HUMANIZED PERSONNEL MANAGEMENT PRACTICES AND \\ ORGANIZATION OF LABOR: BEYOND POSITIVISM AND DATAISM
}

\begin{abstract}
Pedro Afonso Cortez ${ }^{1}$ (D) (0000-0003-0107-2033), Thais Zerbini² iD (0000-0001-6799-3658), Heila Magali da Silva Veiga ${ }^{3}$ iD) ${ }_{(0000-0002-7429-8124)}$
\end{abstract}

\author{
${ }^{1}$ Universidade São Francisco, Programa de Pós-graduação Stricto Sensu em Psicologia, Campinas, São \\ Paulo, Brasil. \\ <cor.afonso@gmail.com> \\ ${ }^{2}$ Universidade de São Paulo, Faculdade de Filosofia, Ciências e Letras de Ribeirão Preto, Ribeirão Preto, \\ São Paulo, Brasil. \\ ${ }^{3}$ Universidade Federal de Uberlândia, Instituto de Psicologia, Programa de Pós-graduação Stricto Sensu \\ em Psicologia, Uberlândia, Minas Gerais, Brasil.
}

Resumo A humanização é um importante arcabouço teórico-prático para a transformação social das organizações e gestão de pessoas, pois promove políticas e práticas inclusivas e de desenvolvimento para trabalhadores, gestores e instituições. Enfatizando essa compreensão, este ensaio abarcou concepções críticas dos fenômenos organizacionais para contribuir na análise de práticas de gestão humanizadas em organizações sociais. O campo teórico-prático das práticas de gestão e organização do trabalho foi analisado, destacando a ineficácia do positivismo instrumental, práticas administrativas de recursos humanos e dataísmo. Também foram transpostos aos contextos de trabalho, elaborações contemporâneas sobre práticas organizativas, dialógica, prática políticopedagógica, libertação versus dominação e análise de implicação. Destacamos essas contribuições como formulações iniciais para proporcionar condições organizacionais e de gestão do trabalho humanizadas. Essas elaborações também podem ser úteis para visualizar práticas negativas e dar maior visibilidade a ações e práticas que possibilitem aos sujeitos, às organizações e à própria sociedade condições de 'ser mais' .

Palavras-chave humanização da assistência; gestão em saúde; administração em saúde; administração de recursos humanos, análise de implicação.
Abstract Humanization is an important theoreticalpractical framework for the social transformation of organizations and personnel management because it promotes inclusive and developmental policies and practices for workers, managers and institutions. Emphasizing this understanding, the present essay encompassed critical conceptions of the organizational phenomena in order to contribute to the analysis of humanized management practices in social organizations. The theoretical-practical field of the practices of management and organization of labor was analyzed, highlighting the inefficacy of the instrumental positivism, administrative practices of human resources and dataism. Contemporary elaborations regarding organizational, dialogical and political-pedagogical practices, liberation versus domination and an analysis of implications were also transposed to the labor contexts. We highlight these contributions as initial formulations to provide humanized labor management and organizational conditions. These elaborations may also be useful in order to visualize negative practices and to give more visibility to actions and practices that enable the subjects, the organizations and even society itself to have conditions to 'be more'.

Keywords humanization of care; management in health; administration in health; human resources administration; implication analysis. 


\section{Introdução}

Compreender a humanização como um processo de desenvolvimento contínuo das pessoas e da realidade social é fundamental para impactar em melhores condições de vida, trabalho e saúde física e mental em diferentes organizações (Dale e Hyssop-Margison, 2010). Com esse intuito, o presente estudo presta contribuições para fomentar práticas humanizadas de gestão de pessoas e organização do trabalho, a fim de que essa concepção se torne predominante nos espaços laborais. Neste ensaio, a tentativa de compreensão da realidade transpassa pela historicidade da própria constituição humana, entendida como espaço-tempo discursivo do processo de humanização (Freire A., 2001; Roberts, 2007).

Em um sentido amplo, a humanização refere-se aos processos de interação que possibilitam aos indivíduos adquirirem características próprias do convívio social humano capazes de transformar o contexto em que se inserem e suas próprias realidades (Dale e Hyssop-Margison, 2010). Em uma concepção aplicada, advém da ideia de tornar-se mais humano pela participação nas diferentes instâncias culturais e seus ritos (família, escola, trabalho etc.) de forma harmônica e coesa (Hobson et al., 2018). Assim, para alcançar esse propósito, faz-se preciso que o tema se torne central nas organizações sociais e em suas práticas, razão pela qual torna-se fundamental promovê-la em diferentes espaços sociais.

Desta forma, é possível ensaiar a humanização como prática em diferentes processos organizacionais, uma vez que a dinamicidade e abrangência desta concepção não limita as contribuições às instituições educacionais e de saúde. Isso é visível ao observar estudos contemporâneos, que traçaram bases sobre a humanização em diferentes perspectivas, os quais possibilitam apreender formas otimizadas de produzir a socialização e as interações entre agentes sociais nos contornos de diferentes épocas, capazes de fomentar insights para a humanização em nosso tempo (Glass, 2013).

No presente ensaio, abrangem-se algumas contribuições freireanas e de teóricos organizacionais, com o intuito de ensaiar por meio delas formas de organização e gestão humanizadas. Destarte, salienta-se a importância dessas fundamentações ao se abranger o contexto atual, pois perpassa por dois tópicos recorrentes em contextos organizacionais: a insuficiência do racionalismo instrumental; e a dificuldade de se vislumbrar alternativas a esse modelo que não implique maior precarização social e do trabalho (Cortez et al., 2017). Ademais, a lógica da crise, como prática discursiva que mantém funcional o racionalismo instrumental, parece não manter os ânimos sociais alheios da insuficiência das práticas exclusivamente tecnicistas, o que incide em convulsões sociais em busca de novas formas de organização e gestão do trabalho (Cortez e Souza, 2017). Assim, com o intuito de contribuir nesses 
aspectos, objetivou-se abarcar concepções críticas frente aos fenômenos organizacionais e laborais com o intuito de fomentar práticas humanizadas de gestão de pessoas e organização do trabalho.

\section{Ponto de partida: limitações e reinvenções do positivismo instrumental}

Desde a segunda metade do séc. XIX, há uma crescente concordância de que a lógica positivista predominante em algumas Ciências Humanas e Sociais Aplicadas se apresentam insatisfatórias para abarcar adequadamente os fenômenos organizacionais. Compreender as organizações sociais demanda apreender a contingencialidade, multideterminação e historicidade que interferem na compreensão dos fenômenos educativos e laborais (Freire A., 2001). Neste sentido, dimensionar as organizações sempre implica inscrevêlas em função de sua própria história e interrelações com outros agentes contextuais e atores sociais que determinam a produção de sentido e ordenação do trabalho dentro daquele espaço-tempo (Jaramillo, 2010).

No momento atual, a desumanização, além de abranger as organizações como espaço cultural e institucional, também se insere por meio de outros instrumentos que intersecionam o cotidiano dos trabalhadores (Fleuri, 2008). As mídias digitais e a cibercultura, que se desenvolvem como novos espaços de convívio ampliado, exemplificam as plataformas para controle integral dos trabalhadores e alienação social das pessoas de forma geral (Jarrett, 2008). Especificamente, as redes sociais que, como desdobramento recente dos fenômenos de globalização e revolução digital, demonstram-se um campo fértil para a reinvenção do positivismo lógico e contínua aplicação da racionalidade instrumental por meio do 'dataísmo' (Dijck e Nieiborg, 2009).

Na concepção 'dataísta', a informação digital - dados - possui valor supremo e o fluxo informacional obtido de técnicas modernas de análise de dados em grande quantidade - Big Data - representa a forma mais sofisticada para a tomada de decisão de forma empírica (Dijck, 2014). O positivismo, por sua vez, predispõe a realidade como fundamentalmente elaborada em termos empiricamente verificáveis, o que o torna altamente compatível com o 'dataísmo'. Para o positivista, o conhecimento só pode ser concebido a posteriori mediante validação e avaliação das inferências acerca dos fenômenos que se pretende conhecer (Hernandez-Chanto, 2006).

Ao enfatizar o campo concreto material, insere-se no contexto de organizações e trabalho a dificuldade de operacionalizar formas imediatas de apreensão e validação do conhecimento gerado por meio dos dados, o que ressalta a importância de abordagens multimétodos nos espaços laborais e aponta para a ineficácia positivista 'dataísta' estrita (Bacharach, 1989). Contudo, com a virtualização crescente das relações e, consequentemente, de parte das práticas organizacionais, a revitalização do positivismo lógico acontece, 
emergindo maior espaço para a adoção de concepções 'dataístas'. Isso ocorre principalmente por meio das inteligências artificiais, cuja primazia dos dados tendem a reduzir as relações cotidianas aos pares binários e combinatórios de modelagens computacionais, as quais podem ser lesivas à humanização (Balakrishnan, 2016).

Por um lado, essas transposições do real ao computacional se apresentam como uma possibilidade para apreensão dos fenômenos com maior brevidade. Pautando-se no 'dataísmo', essas proposições se vinculam ao discurso instrumental e supostamente neutro, com base no qual assimetrias são relegadas à dimensão implícita (Peters, 2017). Nos aspectos implícitos, encontram-se os condicionantes que devem ser avaliados para verificar em que medida o processamento informacional imediato impacta em maior controle ou empoderamento dos atores sociais inseridos na organização de trabalho, demonstrando potencial lesivo ou propulsor à humanização (Dijck, 2014). Torna-se fundamental, portanto, apreender a dimensão implícita inerente às propostas 'dataístas', com o intuito de visualizar os agentes sociais e interesses inscritos nessas ações de desenvolvimento e avaliação, uma vez que, sem compreender seus mediadores intrínsecos, dificilmente é possível visualizar seus prováveis impactos (Fuenfschilling e Binz, 2018).

\section{Sem ponto de chegada: armadilhas paradigmáticas e 'desreferências'}

Um elemento importante ao se analisar as formas de organização que contribuem efetivamente para a humanização das práticas de gestão de pessoas inclui a identificação paradigmática da atuação e o argumento referente. Isto é, dimensionar adequadamente que toda prática apresenta um conjunto de verdades e mediações tomadas como universais ou necessárias que embasam o discurso e dotam de legitimidade a atuação (Jost, Federico e Napier, 2009). Compreender as organizações por meio da Saúde do Trabalhador e Gestão de Pessoas, cujas contribuições aproximam-se de correntes psicossociais e interdisciplinares, é diferente de apreendê-la por meio de um recorte do campo pelas práticas de Administração de Recursos Humanos, mais próximas do positivismo lógico, por exemplo (Viana, Martins e Frazão, 2017).

Nas duas proposições, avanços podem ser obtidos para as organizações e trabalhadores, mas as alternativas críticas de Gestão do Trabalho devem ser priorizadas àquelas exclusivamente administradas na promoção da humanização (Santini et al., 2017). Desta forma, para que seja possível dimensionar adequadamente a prática a ser realizada e o que se espera alcançar, é fundamental que os gestores tenham prévio conhecimento sobre as origens dessas formas de atuação, quais seus pressupostos e objetivos, de modo a vislumbrarem com maior acurácia as implicações esperadas ao efetivá-las. Em condições adequadas de ensino das práticas organizativas e de gestão de pessoas, 
espera-se que os futuros gestores sejam expostos à multiplicidade teórica e prática desse campo para que possam arbitrar criticamente sobre quando aplicar cada uma das propostas supracitadas em função da contingência que se mostra relevante à organização (Cortese, 2005).

No entanto, ao se avaliar as práticas de ensino efetivadas neste campo, nota-se uma grande lacuna no que tange ao menos a dois aspectos: 1) restrição da diversidade paradigmática de atuação lecionada; e 2) ausência de análise crítica do educador mediante a própria prática docente. Essas duas condições levam os potenciais gestores à alienação e total 'desreferenciamento' de suas práticas, que é mantida desta forma pela impossibilidade dos estudantes que atuarão como futuros gestores pensarem criticamente sobre o que fazem, por qual razão o fazem e quais as consequências de suas práticas para os sujeitos inseridos no ambiente laboral (Menezes e Santiago, 2014).

$\mathrm{O}$ 'desreferenciamento' acontece, portanto, quando a prática educativa falha em seu propósito final - a humanização das pessoas e das realidades - relegando ao futuro gestor unicamente a condição de replicar as práticas que apreendeu no ciclo formativo em função da utilidade contingencial de demandas situacionais (Silva, Sakamoto e Gallian, 2014). Não há na ação do gestor um projeto estratégico, progressista e libertador da realidade laboral, uma vez que a lacuna educativa não permite que os aprendizes desenvolvam consciência sobre as realidades que se inserem, seus lugares sociais e os tensionamentos ideopolíticos que constituíram o aporte teórico-prático de atuação, nem a própria organização (Medeiros e Batista, 2016). A prática organizativa e de gestão de pessoas adquire exclusivamente uma dimensão técnica, instrumental, cuja racionalidade é tomada como propósito primeiro e último do exercício organizativo, que se torna alheio às implicações passíveis de ocasionar pleno desenvolvimento humano nas organizações de trabalho (Fournier e Grey, 2000).

É por meio da superação do tecnicismo e ações exclusivamente administradas que as práticas das organizações podem se tornar humanizadas. Para tanto, é fundamental compreender concepções como dialógica, prática político-pedagógica, libertação e implicação, como via de superação do 'desreferenciamento' rumo à viabilização de condições humanizadoras. Essas concepções são fundamentais, pois se mostram atreladas às condições educacionais de libertação e/ou alienação dos homens na realidade concreta e de suas possibilidades existenciais.

\section{Contribuições às práticas humanizadas de gestão de pessoas e organização do trabalho}

No recorte deste ensaio, as organizações humanas são apreendidas como espaços de execução de tarefas por um corpo coletivo com discursos alinhados 
para a aplicação de esforços e insumos em favor de objetivos comuns. Podem abranger diferentes áreas - saúde, educação, indústria, comércio e serviços - e segmentos - público, privado e terceiro setor (Styhre, 2004). Estruturalmente, as organizações humanas podem adquirir diferentes formatos, sendo preferíveis para aquelas que pretendem promover a Humanização o uso de equipes de trabalho no formato de redes, cuja departamentalização seja flexível, funcionando transitoriamente no formato de projetos, com o intuito de permitir a fluência dialógica e difusão dos conhecimentos de maneira complementar e transversal entre gestores e trabalhadores (Cardoso e Hennington, 2011).

Em setores de saúde, indústrias e outras organizações, as normas regulamentadoras das atividades podem exigir estruturas com maior verticalização e segmentação dos trabalhadores (Brasil, 1978). Nesses casos, ainda que os vínculos humanizados sejam prejudicados, o foco estrutural deve priorizar a saúde e a segurança do trabalhador, abrangendo a economia psicossomática e a carga vivenciada no trabalho, relatada pelo trabalhador como prioridade na definição das unidades produtivas e operacionais. Isso é fundamental, pois nas situações em que o relato do trabalhador é tomado como primazia emerge-se a condição básica de qualquer proposta humanizada: o efeito relacional do recurso dialógico que só pode ser aplicado mediante a expressão do relato discursivo dos atores sociais inseridos em determinado espaço-tempo (Klikauer, 2017).

\section{Dialógica: discurso como fonte de gestão de pessoas e organização}

O espaço-tempo é fundamental para se aprofundar nas concepções de dialogia e produções discursivas, uma vez que as vivências, tensionamentos e ideopolíticas que agem sobre os processos psicossociais se retroalimentam do 'espírito de época' para condicionar as expressões e representações dos (e sobre) os sujeitos, organizações e sociedade (Béland e Cox, 2010). Conceber as práticas organizativas e de gestão de pessoas antes e após o advento da Administração Científica proposta por Taylor diferencia-se da apreensão desses fenômenos no contexto atual de crescente globalização, revolução tecnológica, precarização social e do trabalho (Baraldi et al., 2008; Martins, 2005; Matta, 2005). No presente momento, é comum que o principal recurso discursivo se torne a ideologia de excelência como retórica para atribuição intraindividual sobre os fatores condicionantes das práticas organizativas e da realidade das organizações (Finazzi-Santos e Siqueira, 2011).

Ainda nessa concepção, as práticas organizativas e de gestão de pessoas desconsideram o entorno da organização, as relações sócioprodutivas que ali se formam e o conflito inerente à historicidade, pois empregam o 'desreferen- 
ciamento' e a suposta neutralidade como forma de preconizar os interesses hegemônicos (Smith, 2007). Em nosso contexto de época, o neoliberalismo, que se fortalece desde 1990 e se reinventa atualmente por meio do 'dataísmo' desenfreado como discurso implícito em políticas e práticas propostas às organizações de trabalho, busca suprimir as falas e saberes populares dos trabalhadores e das coletividades, por meio de indicadores de larga escala desenvolvidos por especialistas que aplicam o conhecimento em suas respectivas subáreas de atuação (Harvey, 2007).

Nesses indicadores, a suposta neutralidade traz consigo a ideopolítica neoliberal e a primazia dos saberes dos especialistas, que se propõem verticalmente aos contextos laborais (Flew, 2014). Torna-se fundamental, por isso, questionar criticamente o uso dessas propostas conjuntamente àqueles impactados por essas decisões ao se buscar maior humanização. Nas propostas de gestão de pessoas e organização humanizadas do trabalho, a realização de assembleias consultivas e dialógicas entre especialistas, trabalhadores e agentes de interesse apresenta o caminho conciliatório para que as macropolíticas que dirigem as organizações emerjam do tensionamento das produções discursivas populares e eruditas (Eberhardt e Carvalho, 2016). Não se propõe aqui princípios para definir o início ou fim dessas propostas conciliatórias. Busca-se apenas elencá-las para que o 'desreferenciamento' dê espaço a um entendimento coletivo que surja de uma produção discursiva contextualizada entre os agentes de interesse, a qual deve arbitrar sobre os princípios e consequências aceitáveis frente ao processo organizativo e sobre a prática de gestão de pessoas existente no espaço laboral. Isso é fundamental, inclusive, para que as propostas 'dataístas' fundamentadas em evidências empíricas sejam compreendidas e passíveis de adesão pelos trabalhadores e gestores. Caso contrário, mantêm-se distanciamento entre os modelos e indicadores criados pelos especialistas e suas compreensões discursivas e aquelas efetivadas pelos trabalhadores e gestores, que não convergem em condições de desenvolvimento e humanização para nenhuma das partes (Ayala e Oliveira, 2007).

Essa compreensão é basal, pois sem apreender a noção de discurso como forma de mediação e negociação das realidades, relações e práticas, naturalizam-se as condições do espaço-tempo como objetivamente realistas, o que inviabiliza a dialógica discursiva como fonte geradora das práticas de gestão de pessoas e organização do trabalho. Afinal, por meio do referencial realista, a condição única e inequívoca da realidade se vale do 'fisicalismo' como aporte para compreensão do mundo social (Fairclough, 2005). Em um sentido estrito, essa concepção pode se mostrar vantajosa para impactos concretos e imediatos em microcontextos, mas acaba por suprimir outras macrodimensões como o aspecto político e pedagógico inscrito nas relações e práticas humanas, que são fundamentais ao se propor a humanização. 


\section{Prática político-pedagógica: por uma gestão de pessoas e organização para o desenvolvimento}

Um aspecto central entre as macrodimensões é a prática político pedagógica. Essa prática consiste em reconhecer a atividade de gestão de pessoas e a própria organização como um meio para transformação da realidade social pautada em relações laborais voltadas ao constante aprimoramento e aprendizagem dos trabalhadores e da própria empresa (Zerbini e Abbad, 2010). Em um sentido amplo, toda prática precede por uma concepção relacional e teleológica da atividade sobre a forma como as ações são desenvolvidas e para que fim prestam. Na perspectiva humanizada, as relações são inscritas na prática por uma dimensão política, que incide na concepção negociada e tensional dos fazeres dentro do campo. É também pedagógica, pois as negociações existentes para a efetivação da prática só alcançam a humanização quando se propõem por meio de trocas e relações próximas de aprendizagem e construção mútua dos saberes entre os atores sociais envolvidos (Bornstein e Stotz, 2008).

Inexiste, portanto, humanização sem o prévio estabelecimento de macroestratégias capazes de orientar a teleologia da organização e das práticas de gestão de pessoas em favor de constante aprendizagem e desenvolvimento dos trabalhadores e gestores (Bittencourt, 2017). Para isso, a própria organização deve contar com mecanismos capazes de facilitar o desenvolvimento de pessoal e mantê-los constantemente alinhados frente às concepções de práticas político-pedagógicas humanizadas. Em síntese, a prática político-pedagógica na humanização existe como sinônimo de desenvolvimento humano, organizacional e social, pois é um fazer inclusivo e transformador que visa à mudança das condições institucionais em favor do bem-estar coletivo dentro e fora das instituições laborais.

Não se trata, então, de desenvolver subsistemas de treinamento, desenvolvimento e educação de pessoal como simples processo organizativo, muito menos do delineamento de gestão do conhecimento e promoção de criatividade, liderança e inovação, por meio de conteúdos e agendas exclusivas dos saberes eruditos e fazeres técnicos (Freitas, Motta e Mello-Carpes, 2015). Efetivar o desenvolvimento como prática político-pedagógica requer uma análise detalhada do contexto e das necessidades dos sujeitos e das organizações para delinear as ações humanizadas (Cavalcanti e Guizardi, 2018; Martins, Zerbini e Medina, 2018; Meneses e Zerbini, 2009). Nessa análise, os saberes populares e o papel ativo de todos os agentes interessados na organização se fazem importantes, pois é por meio da conciliação entre as diferentes demandas e olhares que as necessidades concretas podem ser apreendidas substancialmente em favor da coletividade (Santorum e Cestari, 2011). 
Por esse motivo, a prática político-pedagógica no princípio de humanização só pode ser efetivada e proporcionar sua finalidade última - o desenvolvimento pessoal, organizacional e a libertação do homem no devir da história - quando é pensada em função dos tensionamentos que a despertam, o que demanda abranger aspectos inscritos dentro e fora das organizações de trabalho. Por isso, a importância de se apreender de forma estratégica e relacional o aporte teórico-prático a ser implementado (Kuenzer, 2004). No cotidiano institucional, o desafio que se apresenta para efetivá-la na humanização reside na dificuldade de incluir os saberes e expressões populares em modelos de gestão de pessoas, que tradicionalmente se respaldam no tecnicismo, nas experiências dos gestores e na verticalização das relações, tal como comumente ocorre nas práticas administradas (Bedani e Veiga, 2015). Para superar essa limitação, é fundamental adotar aportes práticos e político-pedagógicos críticos e alternativos às práticas exclusivamente administradas quando se busca promover a humanização, uma vez que é possível abranger por meio deles considerações acerca do contraditório institucional e social que impliquem mediações favoráveis à libertação e ao bem-estar da coletividade.

\section{Libertação: em favor de gestão de pessoas e organizações inclusivas e trans- formadoras}

Em grande parte, as práticas administradas, apesar de se diferenciarem em função de aportes teóricos sobre as estruturas das organizações e práticas de gestão de pessoas, visam à eficiência e à eficácia da instituição como princípios direcionadores. Ainda que essa orientação sirva para a perpetuação da organização, em termos operacionais e financeiros, e possibilite a manutenção dos vínculos laborais daqueles que nelas se inserem, isso não significa que as condições oferecidas para o trabalho e o objetivo da organização se mantém interessante socialmente (Carneiro e Martins, 2015). As políticas de lean management ocasionadas pela reestruturação produtiva e a crescente precarização dos vínculos e direitos associados ao trabalho demonstram a tendência ascendente de desumanização das organizações, com o intuito de assegurar exclusivamente a teleologia administrada: a efetivação da atividade-fim (Junges, Barbiani e Zoboli, 2018) e a viabilidade econômico-financeira das instituições (Goulart, Lacaz e Lourenço, 2018).

Em situações como essa, principalmente naquelas que também são contornadas por períodos de crise, em que os atores sociais perdem o sentimento de coletividade e passam a operar pela lógica administrada com o intuito de assegurar a simples subsistência, a dominação passa a ser a tônica das práticas organizativas. Nesses cenários, os trabalhadores tendem a consentir com os abusos e a retirada de direitos como uma forma de se manter no trabalho em 
contextos precarizados (Porto, 2017). Os gestores e até mesmo os trabalhadores passam a denunciar e perseguir os próprios pares operando na lógica desumanizada e administrada vigente na organização.

Nos períodos de crise, institui-se também um clima social de que até mesmos os oprimidos devem se tornar opressores para que a organização consiga se replicar (Freire P., 1987). Há, implicitamente, nessa dinâmica, uma mensagem própria da desumanização, que tende a reverberar nas práticas e organizações que vivenciam esses estados precarizados: a dominação e desumanização é a única forma legítima e viável de manter a empresa em funcionamento. Logo, qualquer desvio dessa lógica é retalhado pelo grupo, que tende a torná-la cada vez mais radical e central, o que pode ocasionar, até mesmo, situações em que a tortura, o assédio físico e moral e outras barbáries sejam legitimadas por meio de práticas organizativas e de gestão de pessoas (Freire P. A., 2008).

Nesse ponto, surge, então, o dilema ético que proporciona espaço à humanização nas práticas de gestão de pessoas e organização de forma transformadora: em que medida é 'desejável', 'saudável', 'útil', 'interessante' ao progresso social e ao desenvolvimento dos próprios homens a replicação de instituições em crise e socialmente 'adoecidas'? Principalmente na América Latina, onde a concentração de renda e desigualdade galopante deixada como herança pelas ditaduras e oligarquias demonstram cotidianamente os efeitos negativos de práticas administradas e organizações adoecidas como dispositivos des-humanizadores em nossa realidade (Andreazzi e Bravo, 2014).

Merece especial destaque em nosso contexto atual as instituições do meio político, por meio das quais os ideais de dominação e desumanização instituídos no homem brasileiro médio - sujeitos com mentalidades conservadoras suscetíveis às fake news e desvios de interpretação gerados nas mídias digitais - apresentaram consequências graves ao processo de democratização, libertação e desenvolvimento das instituições nacionais (Flach, 2012). Sobre o brasileiro médio, cabe ressaltar que as experiências educacionais formais e informais, a qualidade das relações sociais e laborais, entre outros aspectos, definem o grau em que as pessoas e, consequentemente, as instituições se tornam suscetíveis à desumanização. Desta forma, os argumentos de 'desreferenciamento', de que alguns grupos sociais se utilizam para replicar a desumanização, seja na esfera política ou dentro das instituições laborais com práticas exclusivamente administradas, tendem a impactar em maior grau sujeitos e instituições que vivenciam maior vulnerabilidade social (Mosse, 2010).

É fundamental salientar ainda o momento presente, no qual representantes de classes militaristas e religiosas neopentecostais apresentam o 'desreferenciamento' como 'nova política' progressista e supostamente humanizada para gestão das instituições democráticas, mas implicitamente promovem mais do mesmo: aquilo que já se encontra instituído nos mecanismos de poder e, recentemente, foi visibilizado por meio dos grandes escândalos de corrupção 
(Ramos e Santoro, 2017). Em partes, isso acontece, pois, ao longo de todo esse processo, a dominação e controle administrado são cooptados em dois níveis distintos: pessoal e social.

Na vida do sujeito, a cooptação acontece como aniquilação identitária; o oprimido se identifica com o opressor e quer fazer parte dos grupos de poder ao efetivar as práticas de dominação. Na esfera social e organizacional, tudo aquilo que pode imprimir uma nova mentalidade e fazer com que as instituições, organizações e práticas cotidianas e de gestão de pessoas sirvam ao propósito transformador em vez da dominação é 'suprimido', 'censurado', 'negado' e rotulado como 'indesejável' (Freire P., 1987).

É no meio dessa cooptação que o aporte crítico alternativo às propostas administradas emerge como proposta disruptiva do ciclo estabelecido, em favor de mediações que ocasionem a libertação da coletividade, em nível pessoal e social. Nas práticas de gestão de pessoas e organização, essa possibilidade alternativa inicia-se com a aplicação de uma concepção contracorrente, tal como a humanização, em que práticas político-pedagógicas inclusivas e transformadoras são efetivadas. Conceber inclusão e transformação incide, por isso, em reconhecer as práticas de gestão e de organização como desenvolvimento social vinculado a um propósito maior que a própria replicação da atividade fim da organização (Cotta et al., 2013). Resulta, por isso, na expansão do propósito institucional em que as organizações se tornam abertas aos diferentes referenciais e, com base na interlocução entre eles, é que se torna factível assegurar o processo de libertação desencadeado pela humanização. Com maior diversidade e uma postura de escuta e integração ativa dos saberes, de forma dialógica, findam-se as falsas dicotomias, o pensamento dualista e a noção de mundo maniqueísta - vigente no brasileiro médio - que tornam os contextos precarizados ainda mais fragilizados e profícuos às rotinas exclusivamente administrativas, excludentes e aos discursos de dominação (Luna, 2017).

Em termos práticos, a organização humanizada age em favor da libertação como estratégia que incide nos microcontextos por meio de práticas de gestão de pessoas e organização favoráveis à diversidade, que se ancoram na macropolítica organizacional, a qual busca o desenvolvimento de ações transversais em favor dos trabalhadores e da sociedade em um sentido geral (Cardoso e Hennington, 2011). A replicação da organização humanizada associa-se inerentemente a este propósito, sem o qual não é possível viabilizar ações transformadoras, cujo progresso concreto incida no desenvolvimento das pessoas e da própria sociedade em que a instituição se insere.

Cabe apontar ainda para a insuficiência dessas ações em microcontextos isolados, as quais não asseguram plenas condições de efetivação da transformação e libertação preconizadas pela humanização. A transformação social advém da integração em rede entre diferentes dispositivos que fazem uso de práticas e princípios organizacionais e de gestão de pessoas humanizados. 
Conjuntamente, esses dispositivos propiciam a transformação do status social do trabalhador, possibilitando promover agentes multiplicadores conscientes das realidades laborais e da sociedade em que se inserem (Matias, Verdi e Finkler, 2016). São esses agentes multiplicadores - sinergicamente em dimensão coletiva e em oposição à mentalidade conservadora dos homens médios pautados em exclusão e dominação - que alcançam condições para que a libertação aconteça em um sentido ideopolítico em diferentes espaços sociais, incluindo as empresas, por exemplo (França e Muniz, 2011).

Contudo, tendo em vista a multideterminação desse processo e a diversidade de atores sociais envolvidos, propõem-se algumas questões: como é possível apreender em que sentido caminham as propostas organizativas e de gestão humanizada de pessoas? Reconhecer os conflitos de interesse e diagramar as forças implícitas que acarretam nas consequências aos atores sociais envolvidos no processo é um caminho relevante para responder esses questionamentos, os quais podem ser balizados pela análise de implicação.

\section{Implicação: análise dos conflitos de interesses e consequências humanizadas}

Nas correntes institucionalistas, é comum a análise da oferta e demanda, da posição do analista institucional e do estado institucional para compreender os vetores que interferem na prática institucional (Rossoni e Silva, 2010). Essas análises são fundamentais no Institucionalismo, pois possibilitam afirmar que o desenho interventivo proposto e as consequências de delineá-lo se afirmam como intervenção (ação puramente instrumental) ou análise (ação consciente e transformadora). No caso da análise de implicação elencada no presente ensaio, além dos aspectos amplamente difundidos pelo Institucionalismo, acrescentam-se reflexões próprias sobre a dialogia, prática político-pedagógica e se opera como intuito final de obtenção da humanização (Chianca, Patton e Ceccon, 2018).

Como proposta para apurar conflitos de interesse e consequências humanizadas, a análise de implicação pode ser apreendida ao menos de duas formas disparadoras. No formato disruptivo, adota-se a implicação como verbo transitivo indireto. O sentido dessa análise é a busca pela posição que se afirma na negação. No caso, ser incompatível, não estar de acordo (Chianca e Ceccon, 2017). Um sujeito talvez implique com os acordos estabelecidos previamente, caso não sejam cumpridos. O objetivo central do formato disruptivo é trazer à tona as negações e descumprimentos dos contratos coletivos, com o intuito de apontar para as dissociações normalmente ignoradas. A posição de se 'implicar com' demarcando a discordância, traz o tópico à tona e cria caminhos de conciliação entre aqueles que são afetados pela questão e, portanto, devem ter vez e espaço para 'implicar com' as práticas e formas de gestão de pessoas no intuito de buscar representatividade e equidade nessas proposições. 
No modelo consequencial, elege-se a implicação como verbo transitivo direto. Essa concepção almeja antecipar a finalidade para maximizar os benefícios e minimizar os riscos e possíveis danos ocasionados aos participantes. Em momentos de elevada mudança ou frente às crises, em que é necessário agir prontamente, esse tipo de análise pode ser útil, seja a priori ou a posteriori, para maximizar a efetividade da prática proposta e assegurar o máximo de bem-estar ao coletivo envolvido. Nos casos em que se conta com maior tempo para planejamento prévio, a antecipação das implicações é preferível para evitar desdobramentos negativos futuros (Chianca; Patton e Ceccon, 2018).

Frente às práticas de organização e gestão de pessoas, especificamente àquelas humanizadas, as duas formas podem ser empregadas. Em espaços de investigação, é bastante comum nos contextos de pesquisa-ação a análise de implicação consequencial a posteriori, ao passo que, em delineamentos correlacionais e experimentais, a análise de implicação consequencial a priori se mostra mais indicada (Yeomans, 2017). A análise de implicação ensaiada para apreensão dos espaços laborais diferencia-se das propostas investigativas ao manter sempre como consequencial o foco da ação humanizada. Busca-se por meio dela responder de que forma os resultados, efeitos e o destino final da proposta organizativa e de gestão de pessoas, implica melhorias e humanização para os trabalhadores e para a organização ou dominação em vez de transformação. Algumas reflexões que podem surgir após a análise de implicação e diagramação de tensionamentos sobre fenômenos distintos são relacionados no Quadro 1.

\section{Quadro 1}

\begin{tabular}{|c|c|}
\hline lagramação para análise de implicação de práticas organizativa & e de gestão de pessoas \\
\hline Fenômeno: & Fenômeno: \\
\hline Gig Economy & Economia Solidária \\
\hline (Stewart; Stanford, 2017) & (Laville, 2009) \\
\hline Princípios identificados: & Princípios identificados: \\
\hline Tecnicismo & Dialogia \\
\hline Prática de suposta neutralidade & Prática político-pedagógica \\
\hline Dominação & Libertação \\
\hline $\begin{array}{l}\text { Trabalhadores submetidos ao discurso de livre concorrência, } \\
\text { autorregulação do mercado e suposta liberdade para o trabalho } \\
\text { desempenham turnos exaustivos diariamente, sem qualquer } \\
\text { tipo de garantias legais e vínculos formais com as organizações } \\
\text { fornecedoras de aplicativos móveis. }\end{array}$ & $\begin{array}{l}\text { Trabalhadores dialogam em favor da cocriação das práticas } \\
\text { de gestão de pessoas e organização do empreendimento } \\
\text { solidário, que tem como finalidade o propósito de } \\
\text { desenvolvimento local para o qual o empreendimento foi } \\
\text { gerado. As garantias e vínculos são negociados e acordados } \\
\text { pelos agentes de interesse. }\end{array}$ \\
\hline $\begin{array}{l}\text { A finalidade do negócio visa à garantia do lucro para a subsistência } \\
\text { da organização sem abranger considerações acerca dos efeitos } \\
\text { ocasionados pela atividade-fim da instituição. }\end{array}$ & $\begin{array}{l}\text { A finalidade do negócio visa à subsistência da organização, } \\
\text { desde que isso não implique na distorção do propósito } \\
\text { de desenvolvimento social definido coletivamente para o } \\
\text { negócio. }\end{array}$ \\
\hline $\begin{array}{l}\text { Nas relações cotidianas, o trabalhador busca unicamente a } \\
\text { subsistência, coma repetição do ciclo mensalmente para assegurar } \\
\text { condições mínimas de vida, o que mantém o trabalhador isolado e } \\
\text { restrito à mesma estratificação social. }\end{array}$ & $\begin{array}{l}\text { As relações cotidianas implicam em trocas e aprendizagens } \\
\text { constantes entre os trabalhadores, que, pelo elevado nível } \\
\text { de identificação com o propósito humanizado, buscam se } \\
\text { desenvolver e formar agentes multiplicadores da proposta. }\end{array}$ \\
\hline $\begin{array}{l}\text { O modelo de negócio e a organização do trabalho é restrita } \\
\text { aos gestores de alta cúpula, que dirigem o futuro da instituição } \\
\text { mediante aplicação de saberes técnicos e especializados. }\end{array}$ & $\begin{array}{l}\text { O modelo de negócio também tende a se aprimorar } \\
\text { continuamente, uma vez que a interação entre saberes } \\
\text { técnicos e populares dos envolvidos com a instituição } \\
\text { maximiza a dinamicidade em crises. }\end{array}$ \\
\hline
\end{tabular}


Pelo exposto, nota-se que a análise de implicação não é única, nem um modelo fechado. Trata-se de uma proposta dinâmica que se delineia por meio da compreensão dos elementos que medeiam as realidades apreendidas entre saberes e discursos técnicos e populares. O importante na análise de implicação é incluir os múltiplos olhares sobre a questão e permitir que pontos de vista conciliatórios e discordantes - caso existam - sejam trazidos ao referencial analítico (Voronov e Yorks, 2015). Nos casos supracitados, há um mapeamento claro e distinto sobre princípios humanizados e transformadores para a Economia Solidária e de desumanização e dominação para a Gig Economy, que podem servir como disparadores para análises futuras.

Vale ressaltar que os exemplos supracitados não são estáticos. A primazia da análise de implicação é a produção de conhecimento local e contingencial, de forma que cada fenômeno organizacional e prática de gestão de pessoas no seu contexto de expressão terá uma implicação negociada coletivamente, a qual deve ser apreendida para se promover a humanização (Yanow, 2004). Outros casos dos fenômenos supracitados podem exibir hibridismo entre práticas humanizadas e não humanizadas. O fundamental é que a análise de implicação sirva como marco referencial para apreender, negociar e representar a realidade, buscando nela intervir em função de propósitos práticos efetivos e funcionais para a instituição ou fenômeno em análise.

Os objetivos explícitos e implícitos são outras categorias úteis para a análise de implicação. Principalmente quando se propõem novos planejamentos, no caso de mudanças sistemáticas, ou em situações em que se mobilizam esforços para a execução de determinadas atividades com o intuito de responder aos problemas imediatos (Berry e Broadbent, 1988). Como objetivo último, explícito e visível, a consequência normalmente é apreendida ao se analisar indicadores administrados, principalmente em uma perspectiva econômica e financeira. No entanto, conjuntamente a este aspecto explícito, existe também a dimensão consequencial implícita, que é a negação ou antítese daquilo explicitado. Assim, intervir em um sentido implica distanciar-se de outro, que é implicitamente negligenciado, para que se produza um habitus com direcionamento concreto em favor de uma das perspectivas (Crossley, 2013). Nesses casos, a análise de implicação dos aspectos implícitos pode facilitar a identificação de quais mecanismos negligenciados ou intencionalmente ocultos facilitaram o encadeamento das consequências para um direcionamento específico e, baseado nisso, fomentar adequações e intervenções transformadoras.

Outras dimensões importantes que devem ser consideradas nas análises de implicação abrangem: 1) as próprias implicações - valores pessoais, teleologia existencial e realização pessoal (Kaspary e Seminotti, 2012); 2) as implicações da organização - valores organizacionais, missão e impacto da atividade-fim (Baumol, 1996); e 3) as implicações societais - externalidades e responsabili- 
dade ambiental e social (Schwartz, 2004). Deve-se ainda abranger nas práticas organizativas e de gestão de pessoas, principalmente em organizações com estrutura altamente verticalizadas, a análise de implicação do topo à base (top down) e da base ao topo (bottom up), uma vez que as discordâncias e compreensões consequenciais variam de acordo com o fluxo comunicacional e estrato social ou sociolaboral. Também é recomendado que agentes de dentro e de fora da organização façam parte do processo para se apreender a implicação na ótica de agentes internos e externos (Cooren, 2013).

\section{Desenvolvimentos futuros: possibilidades e desafios}

Uma questão recente sobre a implicação, ainda não delineada na literatura, mas que se mostra pertinente em nossa realidade é a superimplicação e subimplicação. Alguns grupos sociais dominantes afirmam que há uma onda crescente de 'politicamente correto' e que, por isso, as pessoas estariam mais 'sensíveis' em diferentes contextos, o que resultaria na superimplicação de alguns grupos minoritários. Para esses grupos sociais dominantes, tudo é passível de implicação pelas minorias, que são nomeadas cotidianamente como 'grupo mimimi'. Isso acontece, pois durante muito tempo as condições sociais relegaram à subimplicação práticas de dominação e violência, de forma que contingências históricas legitimaram o desrespeito às minorias por grupos socialmente dominantes (Solano, 2018).

Assim, principalmente desde a primeira década do século XXI, quando ocorre no Brasil um movimento de tomada de consciência coletiva por minorias - ocasionado por meio da promoção de políticas públicas, ações afirmativas e programas de redução de desigualdades em diferentes espaços -, atores sociais marginalizados passam a ter espaço de representação e voz para implicação. Como efeito primário, as ações afirmativas e as políticas inclusivas possibilitaram às mulheres, às LGBTQs (lésbicas, gays, bissexuais, transgêneros, queers e outras identidades), aos negros e às pessoas com deficiências, maior inclusão estratégica nos espaços organizacionais. Como desdobramento dessa inclusão, a implicação das minorias sobre o desrespeito passa a ser apreendida como superimplicação pelo grupo social dominante, ao passo que se trata unicamente de uma reação implicada com a violência institucionalizada historicamente (Guimarães, 2002).

Isso demonstra que a superimplicação (supostamente exagerada) e subimplicação (supostamente desprezada) não se apresenta de forma linear e, por isso, é dependente de uma narrativa, historicidade e condições organizativas para que seja apreendida corretamente. Nas práticas de gestão de pessoas e organização, principalmente em contextos de 'desreferenciamento', é provável que os gestores e trabalhadores sejam cada vez mais convidados a pensar sobre 'super' e 'sub' implicação, uma vez que critérios objetivos de verdade, 
validade e consequência, tendem a se apresentar difusos com o advento da pós-modernidade e do dataísmo desenfreado (Dijck, 2017).

Ademais, cabe questionar sobre como será possível promover a humanização nesses contextos se os critérios que motivam a teleologia humana tornarem-se cada vez mais difusos e se, com o advento do dataísmo, a cognição e características humanas não se apresentarem mais como formas ótimas de se apreender a realidade. Não há resposta única para esse impasse, mas com o intuito de facilitar propostas futuras sobre o tema sintetizam-se desenvolvimentos que podem tanto contribuir para as práticas de gestão de pessoas e organização humanizada, quanto inviabilizá-las no Quadro 2.

\section{Quadro 2}

\begin{tabular}{|c|c|c|}
\hline \multicolumn{3}{|c|}{ Práticas positivas e negativas para desenvolvimentos futuros em humanização } \\
\hline Fenômeno & $\begin{array}{l}\text { Luz } \\
\text { (Prática positiva) }\end{array}$ & $\begin{array}{l}\text { Armadilha } \\
\text { (Prática negativa) }\end{array}$ \\
\hline $\begin{array}{l}\text { Políticas de } \\
\text { humanização } \\
\text { (Santos-Filho, 2007) }\end{array}$ & $\begin{array}{l}\text { - Abranger os diferentes níveis da organização } \\
\text { e agentes internos e externos. } \\
\text { - Promover ações de educação permanente e } \\
\text { transversalidade dos saberes. }\end{array}$ & $\begin{array}{l}\text { - Enfatizar grupos hierárquicos } \\
\text { específicos para atuação ou } \\
\text { desenvolvimento da humanização. } \\
\text { - Implantar políticas humanizadoras } \\
\text { sem a coparticipação dos agentes de } \\
\text { interesse. }\end{array}$ \\
\hline $\begin{array}{l}\text { Práticas avaliativas } \\
\text { e indicadores } \\
\text { (Dijck, 2017) }\end{array}$ & $\begin{array}{l}\text { - Fundamentar em modelos inclusivos } \\
\text { e representativos dos interesses dos } \\
\text { trabalhadores. } \\
\text { - Delinear propostas úteis para a } \\
\text { retroalimentação e aprimoramento das } \\
\text { práticas de gestão de pessoas. }\end{array}$ & $\begin{array}{l}\text { - Assumir a suposta neutralidade, o } \\
\text { dataísmo e o'desreferenciamento' } \\
\text { como modelo. } \\
\text { - Implementar propostas panotípicas } \\
\text { assediantes de controle excessivo para } \\
\text { subsidiar práticas de dominação. }\end{array}$ \\
\hline $\begin{array}{l}\text { Responsabilidade } \\
\text { social e ambiental } \\
\text { (Spence, 2016) }\end{array}$ & $\begin{array}{l}\text { - Reinvestir diretamente parte do lucro aferido } \\
\text { em bem-estar social e preservação ambiental. } \\
\text { - Cuidar do ambiente, saúde e segurança } \\
\text { laboral e das externalidades geradas pelo } \\
\text { negócio. }\end{array}$ & $\begin{array}{l}\text { - Usar decertificações e } \\
\text { responsabilidade social como } \\
\text { moeda de troca para maior lucro e } \\
\text { negociações imorais } \\
\text { - Empregar a responsabilidade } \\
\text { ambiental como vitrine para atrair } \\
\text { nicho específico de consumidores } \\
\text { interessados. }\end{array}$ \\
\hline $\begin{array}{l}\text { Empreendedorismo } \\
\text { discursivo e social } \\
\text { (Steyaert e Katz, 2004) }\end{array}$ & $\begin{array}{l}\text { - Conhecer os agentes de interesse que } \\
\text { permeiam a organização. } \\
\text { - Conciliar valores e interesses da organização } \\
\text { em função de resultados e bem-estar social. }\end{array}$ & $\begin{array}{l}\text { - Negligenciar e naturalizar práticas de } \\
\text { dominação dos agentes de interesse } \\
\text { interno por conflitos de interesse. } \\
\text { - Desenvolver ações pontuais que } \\
\text { não gerem autonomia ao trabalhador } \\
\text { como agente multiplicador do } \\
\text { empreendimento. }\end{array}$ \\
\hline $\begin{array}{l}\text { Comportamento } \\
\text { Organizacional Positivo } \\
\text { (Luthans, 2002) }\end{array}$ & $\begin{array}{l}\text { - Contribuir com o aprimoramento e } \\
\text { desenvolvimento da organização e das } \\
\text { pessoas. } \\
\text { - Desenvolver valores, competências e } \\
\text { atributos pessoais positivos. }\end{array}$ & $\begin{array}{l}\text { - Restringir o Comportamento } \\
\text { Organizacional Positivo aos aspectos } \\
\text { intraindividuais } \\
\text { - Implementar práticas padronizadas } \\
\text { sobre o tema sem adesão, participação } \\
\text { e interesse do trabalhador. }\end{array}$ \\
\hline $\begin{array}{l}\text { Andragogia } \\
\text { nas organizações } \\
\text { (Rumor et al., 2017) }\end{array}$ & $\begin{array}{l}\text { - Considerar os saberes de populações } \\
\text { tradicionais (indígenas, quilombolas etc.) e } \\
\text { populares. } \\
\text { - Relativizar concepções de 'certo' e 'errado' } \\
\text { em busca de soluções negociadas adequadas } \\
\text { ao contexto. }\end{array}$ & $\begin{array}{l}\text { - Aplicar treinamentos exclusivamente } \\
\text { técnicos. } \\
\text { - Não integrar ações de educação } \\
\text { formal e ampliadas para maximizar } \\
\text { inserção social do trabalhador. }\end{array}$ \\
\hline
\end{tabular}

Fonte: Elaboração própria. 
Com base nas alternativas expostas, verifica-se que frente às práticas organizativas e de gestão de pessoas é possível usar do mesmo aporte para promover a humanização ou resultar em práticas de dominação e exclusão, quando as propostas não são delineadas apropriadamente. A principal dificuldade ao tratar da humanização nas instituições é o uso da nomenclatura como rótulo para a prática organizativa e de gestão de pessoas, com o intuito de fomentar a 'maquiagem organizacional', mas sem assegurar os princípios humanizados que a norteiam (Araújo, 2009). Assim, ainda que a análise de implicação deva ser empregada como proposta contínua nas práticas de gestão de pessoas e organização do trabalho, deve-se destinar maior atenção para o referencial analítico nos casos supracitados, pois isso permite que os tensionamentos sejam apreendidos mais facilmente e, com isso, a humanização efetivamente aconteça nos espaços laborais rumo à 'luz' em vez de rumo às 'armadilhas' (Padilha, 2009).

\section{Considerações Finais}

É relevante destacar que as contribuições propostas por meio do presente ensaio não visam esgotar as possibilidades de compreensão das propostas de humanização. Também não se almeja propor como único modelo passível de implementação para humanização das organizações e das práticas de gestão de pessoas, uma vez que diferentes concepções são capazes de balizar o tema, dando os contornos próprios para objetos que se mostrem relevantes ao contexto de compreensão e intervenção. Cabe abarcar, entre as propostas que demonstram elaborações robustas, as seguintes contribuições: humanização como política pública de saúde (Cotta et al., 2013), humanização como referencial teórico-prático profissional (Medeiros e Batista, 2016) e humanização como mecanismo de promoção de direitos humanos e sociais (Rizzo e Lacaz, 2017), que podem servir à complementação daquelas geradas neste ensaio.

Nas práticas organizativas e de gestão de pessoas, deve-se, portanto, questionar de que forma a humanização se propõe nos espaços laborais, em favor da dialogia e práticas político-pedagógicas, capazes de possibilitar à organização, aos trabalhadores e gestores efetiva libertação e transformação em favor de 'ser mais'. Isso acontece na tomada de consciência das estórias condicionantes, que constituem as histórias das práticas ortodoxas das instituições sociais, as quais podem transformar a existência, propósito dos sujeitos, práticas de gestão de pessoas e organização do trabalho em um 'devir' constante rumo à humanização ou à barbárie (Freire P., 1969). Um indicador teórico-prático proposto no presente ensaio para avaliar a adequação das ações desenvolvidas por meio de princípios humanizados é a análise de implicação que, pelas compreensões estabelecidas ao longo do corrente manuscrito, deve 
se tornar uma proposta permanente nos planejamentos institucionais gerados por gestores que buscam promover práticas humanizadas.

\section{Colaboradores}

Pedro Afonso Cortez contribuiu na elaboração do projeto de pesquisa, criação da proposta de estudo, redação do ensaio e revisão do manuscrito. Thais Zerbini contribuiu na elaboração do projeto de pesquisa, redação do ensaio e revisão do manuscrito. Heila Magali da Silva Veiga contribuiu na redação do ensaio e revisão do manuscrito.

\section{Financiamento}

O presente trabalho foi realizado com apoio da Coordenação de Aperfeiçoamento de Pessoal de Nível Superior (Capes) - Código de Financiamento 001 (Bolsa de Doutorado).

\section{PRÁCTICAS HUMANIZADAS DE GESTIÓN DE PERSONAS Y ORGANIZA- CIÓN DEL TRABAJO: MÁS ALLÁ DEL POSITIVISMO Y DEL DATAÍSMO}

Resumen La humanización es un importante marco teórico-práctico para la transformación social de las organizaciones y la gestión de personas, ya que promueve políticas y prácticas inclusivas y de desarrollo para trabajadores, gestores e instituciones. Enfatizando esta idea, este ensayo abarcó concepciones críticas de los fenómenos organizacionales para contribuir en el análisis de prácticas de gestión humanizadas en organizaciones sociales. Se analizó el ámbito teórico-práctico de las prácticas de gestión y organización del trabajo, destacándose la ineficacia del positivismo instrumental, prácticas administrativas de recursos humanos y dataísmo. También se traspusieron, a los contextos de trabajo, elaboraciones contemporáneas sobre prácticas organizativas, dialógica, práctica político-pedagógica, liberación versus dominación y análisis de la implicación. Destacamos estas contribuciones como formulaciones iniciales para proporcionar condiciones organizacionales y de gestión del trabajo humanizadas. Estas elaboraciones también pueden ser útiles para identificar prácticas negativas y proporcionar mayor visibilidad a aquellas acciones y prácticas que posibiliten a los individuos, las organizaciones y la propia sociedad, condiciones de 'ser más'.

Palabras clave humanización de la asistencia; gestión en salud; administración en salud; administración de recursos humanos, análisis de la implicación. 


\section{Referências}

ANDREAZZI, Maria F. S.; BRAVO, Maria I. S. Privatização da gestão e organizações sociais na atenção à saúde. Trabalho, Educação e Saúde, Rio de Janeiro, v. 12, n. 3, p. 499-518, set.- dez. 2014.

ARAÚJO, José N. G. Qualidade de vida no trabalho: controle e escondimento do malestar do trabalhador. Trabalho, Educação e Saúde, Rio de Janeiro, v. 7, n. 3, p. 573-585, nov. 2009 - fev. 2010.

AYALA, Arlene L. M.; OLIVEIRA, Walter F. A divisão do trabalho no setor de saúde e a relação social de tensão entre trabalhadores e gestores. Trabalho, Educação e Saúde, Rio de Janeiro, v. 5, n. 2, p. 251-270, jul.- out. 2007.

BACHARACH, Samuel B. Organizational theories: some criteria for evaluation. Academy of Management Review, Nova Iorque, v. 14, n. 4, p. 496-515, out. 1989.

BALAKRISHNAN, Sreepriya. Historicizing hypertext and web 2.0: access, governmentality and cyborgs. Journal of Creative Communications, Nova Delhi, v. 11, n. 2, p 102-118, jun. 2016.

BARALDI, Solange et al. Globalização e seus impactos na vulnerabilidade e flexibilização das relações do trabalho em saúde. Trabalho, Educação e Saúde, Rio de Janeiro, v. 6, n. 3, p. 539-548, nov. 2008 - fev. 2009.

BAUMOL, William J. Entrepreneurship: Productive, unproductive, and destructive. Journal of Business Venturing, Amsterdã, v. 11, n. 1, p. 3-22, jan. 1996.

BEDANI, Marcelo; VEIGA, Heila M. S. Práticas organizacionais: uma contribuição teórica. Gerais: Revista Interinstitucional de Psicologia, São João del Rei, Minas Gerais, v. 8, n. 2, p. 428-442, dez. 2015.

BÉLAND, Daniel; COX, Robert H. Ideas and politics in social science research. England: Oxford University Press, 2010.
BERRY, Dianne C.; BROADBENT, Donald E. Interactive tasks and the implicit-explicit distinction. British Journal of Psychology, v. 79, n. 2, p. 251-272, maio 1988.

BITTENCOURT, Renato N. A impossível neutralidade discursiva na práxis educacional e a improbidade ideológica da Escola sem Partido. Revista Espaço Acadêmico, Maringá, Paraná, v. 16, n. 191, dez. 2017.

BORNSTEIN, Vera J.; STOTZ, Eduardo N. O trabalho dos agentes comunitários de saúde: entre a mediação convencedora e a transformadora. Trabalho, Educação e Saúde, Rio de Janeiro, v. 6, n. 3, p. 457-480, nov. 2008- fev. 2009.

BRASIL. Ministério do Trabalho. NR 12: Segurança no trabalho em máquinas e equipamentos. Diário Oficial [da]República Federativa do Brasil, Poder Executivo, Brasília, DF,1978.

CARDOSO, Cíntia G.; HENNINGTON, Élida A. Trabalho em equipe e reuniões multiprofissionais de saúde: uma construção à espera pelos sujeitos da mudança. Trabalho, Educação e Saúde, Rio de Janeiro, v. 9, sup., p. 85-112, set. 2011.

CARNEIRO, Carla C. G; MARTINS, Maria I. C. Novos modelos de gestão de pessoas no setor público de saúde e o trabalho do agente comunitário de saúde. Trabalho, Educação e Saúde, Rio de Janeiro, v. 13, n. 1, p. 45-66, jan.- abr. 2015.

CAVALCANTI, Felipe O. L.; GUIZARDI, Francini L. Educação continuada ou permanente em saúde? Análise da produção pan-americana da saúde. Trabalho, Educação e Saúde, Rio de Janeiro, v. 16, n. 1, p. 99-122, jan. - abr. 2018.

CHIANCA, Thomaz K.; CECCON, Claudius. Pedagogy in process applied to evaluation: learning from Paulo Freire's work in Guineabissau. New Directions for Evaluation, v. 155, n. 1, p. 79-97, fev. 2017.

CHIANCA, Thomaz K.; PATTON, Michael Q.; CECCON, Claudius. Evaluative thinking in 
practice : implications for evaluation from Paulo Freire's work. Journal of Multidisciplinary Evaluation, v. 14, n. 30, p. 1-15, mar. 2018.

COOREN, Francois. Communication as organizing. London: Routledge, 2013.

CORTESE, Claudio G. Learning through teaching. Management Learning, Thousand Oaks, v. 36, n. 1, p. 87-115, mar. 2005.

CORTEZ, Pedro A. et al. A saúde docente no trabalho: apontamentos a partir da literatura recente. Cadernos Saúde Coletiva, Rio de Janeiro, v. 25, n. 1, p. 113-122, jan.- mar. 2017.

CORTEZ, Pedro A.; SOUZA, Marcus V. R. Menos profissionais, mais sujeitos: formação para a educação popular no Sistema Único de Saúde (SUS). Revista de Educação Popular, Uberlândia, v. 16, n. 2, p. 27-37, nov. 2017.

COTTA, Rosângela M. M. et al. Debates atuais em humanização e saúde: quem somos nós? Ciência \& Saúde Coletiva, Rio de Janeiro, v. 18, n. 1, p. 171-179, jan. 2013.

CROSSLEY, Nick. Habit and habitus. Body and Society, Thousand Oaks, v. 19, n. 2-3, p. 136-161, out. 2013.

DALE, John; HYSSOP-MARGISON, Emery J. Paulo Freire: teaching for freedom and transformations. The philosophical influences on the work of Paulo Freire. Netherlands: Springer, 2010.

DIJCK, José V. In data we trust? the implications of datafication for social monitoring. MATRIZes, São Paulo, v. 11, n. 1, p. 39, abr. 2017.

DIJCK, José V. Datafication, dataism and dataveillance: big data between scientific paradigm and ideology. Surveillance and Society, v. 12, n. 2, p. 197-208, maio 2014.

DIJCK, José V.; NIEBORG, David. Wikinomics and its discontents: a critical analysis of Web 2.0 business manifestos. New Media \&
Society, Thousand Oaks, v. 11, n. 5, p. 855874, nov. 2009.

EBERHARDT, Leonardo D.; CARVALHO, Manoela. Gestão do trabalho e organização coletiva de trabalhadores do setor público de saúde. Trabalho, Educação e Saúde, Rio de Janeiro, v. 14, sup., p. 45-65, nov. 2016.

FAIRCLOUGH, Norman. Discourse analysis in organization studies: the case for critical realism. Organization Studies, Thousand Oaks, v. 26, n. 6, p. 915-939, jun. 2005.

FINAZZI-SANTOS, Marcelo A.; SIQUEIRA, Marcus V. S. Considerações sobre trabalho e suicídio: um estudo de caso. Revista Brasileira de Saúde Ocupacional, São Paulo, v. 36, n. 123, p. 71-83, jun. 2011.

FLACH, Leonardo. O jeitinho brasileiro: analisando suas características e influências nas práticas organizacionais. Revista Gestão e Planejamento, Salvador, v. 13, n. 3, p. 499514, out. 2012.

FLEURI, Reinaldo M. Rebeldia e democracia na escola. Revista Brasileira de Educação, Rio de Janeiro, v. 13, n. 39, p. 470-482, dez. 2008.

FLEW, Terry. Six theories of neoliberalism. Thesis Eleven, Thousand Oaks, v. 122, n. 1, p. 49-71, jun. 2014.

FOURNIER, Valérie; GREY, Chris. At the critical moment: conditions and prospects for critical management studies. Human Relations, Thousand Oaks, v. 53, n. 1, p. 7-32, fev. 2000.

FRANÇA, Maristela B.; MUNIZ, Hélder P. A gestão coletiva dos serviços de saúde pública: uma perspectiva ergológica. Trabalho, Educação e Saúde, Rio de Janeiro, v. 9, sup., p. 201-221, nov. 2011.

FREIRE, Ana M. A. Pedagogia da indignação: cartas pedagógicas e outros escritos. Interface: Comunicação, Saúde, Educação, Botucatu, v. 5, n. 8, p. 147-152, fev. 2001. 
FREIRE, Paula A. Assédio moral e saúde mental do trabalhador. Trabalho, Educação e Saúde, Rio de Janeiro, v. 6, n. 2, p. 367-380, jul.- out. 2008.

FREIRE, Paulo. Educação como prática da liberdade. Rio de Janeiro: Paz e Terra, 2011.

FREIRE, Paulo. Papel da educação na humanização. Rio de Janeiro: Paz e Terra,1969.

FREIRE, Paulo. Pedagogia do oprimido. Rio de Janeiro: Paz e Terra, 1987.

FREITAS, Diana P. S.; MOTTA, Cezar S.; MELLO-CARPES, Pâmela B. As bases neurobiológicas da aprendizagem no contexto da investigação temática freireana. Trabalho, Educação e Saúde, Rio de Janeiro, v. 13, n. 1, p. 109-122, jan.- abr. 2015.

FUENFSCHILLING, Lea; BINZ, Christian. Global socio-technical regimes. Research Policy, v. 47, n. 4, p. 735-749, maio 2018.

GLASS, Ronald D. Revisitando os fundamentos da educação para a libertação: o legado de Paulo Freire. Educação \& Realidade, Porto Alegre, v. 38, n. 3, p. 831-851, set. 2013.

GOULART, Patrícia M.; LACAZ, Francisco A. C.; LOURENÇO, Edvânia Â. S. Condições de trabalho e saúde no contexto da previdência social em Santa Catarina. Trabalho, Educação e Saúde, Rio de Janeiro, v. 16, n. 3, p. 1.2371.259, set.- dez. 2018.

GUIMARÃES, Nadya A. Os desafios da eqüidade: reestruturação e desigualdades de gênero e raça no Brasil. Cadernos Pagu, Campinas, v. 17-18, n. 1, p. 237-266, fev. 2002.

HARVEY, David. A brief history of neoliberalism. USA: Oxford University Press, 2007.

HERNANDEZ-CHANTO, Allan. El método hipotético-deductivo como legado del positivismo lógico y el racionalismo crítico: su influencia en la economía. Ciencias Económicas, Costa Rica, v. 26, n. 2, p. 183-195, jun. 2006.

HOBSON, Nicholas M. et al. The psychology of rituals: an integrative review and processbased framework. Personality and Social Psychology Review, Thousand Oaks, v. 22, n. 3, p. 260-284, ago. 2018.

JARAMILLO, Orlanda. La formaciin ciudadana en la obra de Freire. Uni-Pluri/Versidad, Medellín, v. 8, n. 3, p. 1-9, jun. 2010.

JARRETT, Kylie. Interactivity is evil! A critical investigation of Web 2.0. First Monday, Chicago, v. 13, n. 3, p. 1-10, jul. 2008.

JOST, John T.; FEDERICO, Christopher M.; NAPIER, Jaime L. Political ideology: its structure, functions, and elective affinities. Annual Review of Psychology, v. 60, n. 1, p. 307-337, dez. 2009.

JUNGES, José R.; BARBIANI, Rosangela; ZOBOLI, Elma L. C. P. Vulneração programática como categoria explicativa dos problemas éticos na atenção primária à saúde. Trabalho, Educação e Saúde, Rio de Janeiro, v. 16, n. 3, p. 935953, set.- dez. 2018.

KASPARY, Magda C.; SEMINOTTI, Nedio A. Os processos grupais e a gestão de equipes no trabalho contemporâneo: compreensões a partir do pensamento complexo. RAM: Revista de Administração Mackenzie, São Paulo, v. 13, n. 2, p. 15-43,2012.

KLIKAUER, Thomas. Business ethics as ideology? Critique: Journal of Socialist Theory, v. 45, n. 1-2, p. 81-100, abr. 2017.

KUENZER, Acacia Z. Sob a reestruturação produtiva, enfermeiros, professores e montadores de automóveis se encontram no sofrimento do trabalho. Trabalho, Educação e Saúde, Rio de Janeiro, v. 2, n. 1, p. 107-120, mar.- ago. 2004.

LAVILLE, Jean-Louis. A economia solidária: um movimento internacional. Revista Crítica 
de Ciências Sociais, Coimbra, v. 84, n. 1, p. 7-47, mar. 2009

LUNA, Naara. A criminalização da "ideologia de gênero": uma análise do debate sobre diversidade sexual na Câmara dos Deputados em 2015. Cadernos Pagu, Campinas, v. 50, n. 1, dez. 2017.

LUTHANS, Fred. The need for and meaning of positive organizational behavior. Journal of Organizational Behavior, v. 23, n. 6, p. 695706, set. 2002.

MARTINS, André R. N. Grupos excluídos no discurso da mídia: uma análise de discurso crítica. DELTA: documentação de estudos em lingüística teórica e aplicada, São Paulo, v. 21, p. 129-147, out. 2005. Número Especial.

MARTINS, Lara B.; ZERBINI, Thais; MEDINA, Francisco J. Factor structure and psychometric properties of the scale of support for training transfer. Psicologia: Teoria e Pesquisa, Brasilia, v. 34, n. 1, p. e3452, jan. 2018.

MATIAS, Maria C. S.; VERDI, Marta I. M.; FINKLER, Mirelle. A dimensão ético-política da humanização e a formação de apoiadores institucionais. Trabalho, Educação e Saúde, Rio de Janeiro, v. 14, n. 1, p. 55-75, jan.- abr. 2016.

MATTA, Gustavo C. A organização mundial da saúde: do controle de epidemias à luta pela hegemonia. Trabalho, Educação e Saúde, Rio de Janeiro, v. 3, n. 2, p. 371-396, set. 2005 - fev. 2006.

MEDEIROS, Lucilene M. O. P.; BATISTA, Sylvia H. S. S. Humanização na formação e no trabalho em saúde: uma análise da literatura. Trabalho, Educação e Saúde, Rio de Janeiro, v. 14, n. 3, p. 925-951, set. - dez. 2016.

MENESES, Paulo M.; ZERBINI, Thais. Levantamento de necessidades de treinamento: reflexões atuais. Análise Revista de Administração da PUCRS, Porto Alegre, v. 2, n. 1, p. 50-64, jun. 2009.

MENEZES, Marilia G.; SANTIAGO, Maria E. Contribuição do pensamento de Paulo Freire para o paradigma curricular crítico-emancipatório. Pro-Posições, Campinas, v. 25, n. 3, p. 45-62, dez. 2014.

MOSSE, David. A relational approach to durable poverty, inequality and power. Journal of Development Studies, v. 46, n. 7, p. 1.1561.178, ago. 2010.

PADILHA, Valquíria. Qualidade de vida no trabalho num cenário de precarização: a panaceia delirante. Trabalho, Educação e Saúde, Rio de Janeiro, v. 7, n. 3, p. 549-563, nov. 2009 - fev. 2010.

PETERS, Ted. The deluge of dataism: a new post-human religion? Dialog, v. 56, n. 3, p. 211-213, set. 2017.

PORTO, Marcelo F. S. Pode a vigilância em saúde ser emancipatória? Um pensamento alternativo de alternativas em tempos de crise. Ciência \& Saúde Coletiva, Rio de Janeiro, v. 22, n. 10, p. 3149-3159, out. 2017.

RAMOS, Moacyr S.; SANTORO, Ana C. S. Pensamento freireano em tempos de escola sem partido. Revista Inter Ação, Goiânia, v. 42, n. 1, p. 140-158, jun. 2017.

RIZZO, Tamiris P.; LACAZ, Francisco A. C. Limites dos planos de cargos, carreiras e salários para desprecarização das relações de trabalho no SUS. Trabalho, Educação e Saúde, Rio de Janeiro, v. 15, n. 2, p. 399-420, mai.- ago. 2017.

ROBERTS, Peter. Ten years on: engaging the work of Paulo Freire in the 21 st century. Studies in Philosophy and Education, v. 26, n. 6, p. 505-508, jul. 2007.

ROSSONI, Luciano; SILVA, Clóvis L. M. Institucionalismo organizacional e práticas de governança corporativa. Revista de Administração Contemporânea, Curitiba, v. 14, p. 173-198, set. 2010. Número Especial.

RUMOR, Pamela C. F. et al. Educação e cultura em saúde à luz de Paulo Freire. Revista de Enfermagem UFPE Online, Recife, v. 11, n. 12, p. 5.122, dez. 2017. 
SANTINI, Stela M. L. et al. Dos 'recursos humanos' à gestão do trabalho: uma análise da literatura sobre o trabalho no SUS. Trabalho, Educação e Saúde, Rio de Janeiro, v. 15, n. 2, p. 537-559, mai.- ago. 2017.

SANTORUM, Juliana A. C.; CESTARI, Maria E. A educação popular na práxis da formação para o SUS. Trabalho, Educação e Saúde, Rio de Janeiro, v. 9, n. 2, p. 223-240, jul.- out. 2011.

SANTOS-FILHO, Serafim. Perspectivas da avaliação na política nacional de humanização em saúde: aspectos conceituais e metodológicos. Ciência \& Saúde Coletiva, Rio de Janeiro, v. 12, n. 4, p. 999-1.010, jul. 2007.

SCHWARTZ, Yves. Circulações, dramáticas, eficácias da atividade industriosa. Trabalho, Educação e Saúde, Rio de Janeiro, v. 2, n. 1, p. 33-55, mar.- ago. 2004.

SILVA, Marlon R.; SAKAMOTO, Jacqueline; GALLIAN, Dante M. C. A cultura estética e a educação do gosto como caminho de formação e humanização na área da saúde. Trabalho, Educação e Saúde, Rio de Janeiro, v. 12, n. 1, p. 15-28, jan.- abr. 2014.

SMITH, Gavin. Hegemony: a companion to the anthropology of politics. Oxford, UK: Blackwell Publishing, falta data.

SOLANO, Esther. Crise da democracia e extremismos de direita. Análise Friedrich Ebert Stiftung, v. 42, n. 1, p.1-27, maio 2018.

SPENCE, Laura J. Small business social responsibility. Business \& Society, Newbury Park, v. 55, n. 1, p. 23-55, jan. 2016.
STEWART, Andrew; STANFORD, Jim. Regulating work in the gig economy: What are the options? Economic and Labour Relations Review, v. 28, n. 3, p. 382-401, fev. 2017.

STEYAERT, Chris; KATZ, Jerome. Reclaiming the space of entrepreneurship in society: geographical, discursive and social dimensions. Entrepreneurship \& Regional Development, v. 16, n. 3, p. 179-196, maio 2004.

STYHRE, Alexander. The (re)embodied organization: Four perspectives on the body in organizations. Human Resource Development International, v. 7, n. 1, p. 101-116, jan. 2004.

VIANA, Dirce L.; MARTINS, Cleide L.; FRAZÃO, Paulo. Gestão do trabalho em saúde: sentidos e usos da expressão no contexto histórico brasileiro. Trabalho, Educação e Saúde, Rio de Janeiro, v. 16, n. 1, p. 57-78, jan.- abr. 2018.

VORONOV, Maxim; YORKS, Lyle. “Did you notice that?" theorizing differences in the capacity to apprehend institutional contradictions. Academy of Management Review, Briarcliff Manor, v. 40, n. 4, p. 563-586, fev. 2015.

YANOW, Dvora. Translating local knowledge at organizational peripheries. British Journal of Management, v. 15, n. S1, p. 9-25, mar. 2004.

YEOMANS, Liz. Qualitative methods in business research. Action Learning: research and practice, v. 14, n. 3, p. 298-301, ago. 2017.

ZERBINI, Thaís; ABBAD, Gardênia. Aprendizagem induzida pela instrução em contexto de organizações e trabalho: uma análise crítica da literatura. Cadernos de Psicologia Social do Trabalho, São Paulo, v. 13, n. 2, p. 177-193, abr. 2010. 